\title{
Experiential learning with virtual reality: animal handling training
}

\author{
Florence Mei Kuen Tang ${ }^{1 *} \mathbb{D}$, Ray Mau Fung Lee², Roy Hok Lai Szeto³, Justin Chak Ting Cheung ${ }^{1}$ \\ and Olivia Miu Yung Ngan ${ }^{4}$
}

\begin{abstract}
Training in handling laboratory animals is fundamentally imperative to the responsible use of animals in research. Animal welfare topic is underdeveloped in the tertiary education, where instruction is majorly delivered in the format of lecture and group discussion only. Students with limited exposure to the laboratory were inattentive to animal welfare and uncertain how ethics intertwine with science. This paper describes a multi-disciplinary experience in developing and implementing virtual reality (VR) simulation to enhance contextual learning of using animal models in research with digital technology in biomedical science teaching at higher education. The in-house developed courseware consists of student-centred stimulations designed with game elements implemented at the tutorial session. At the first game level, the setting situates at in the preparation room that requires learners to apply the laboratory safety knowledge to wear personal protective equipment. At the second game level, the environment situates at the restricted experimental room to perform hands-on injections on mice. If the learner fails to pick up appropriate safety equipment at the first level, the learner is prohibited from entering the next level. During the simulation, the learner's interaction is also displayed to the monitor that supports parallel teaching to the larger class. At the debriefing, 3Rs principles were reinforced as a sample framework for performing humane animal research. We illustrate how the hybrid uses of VR technology with gamification, together with didactic pedagogy, offers promise in enforcing working knowledge into better task performance, specifically research skills training. Our experience and students' feedback show using immersive VR for educational purposes to encourage the learner applying conceptual knowledge in the simulated laboratory setting. Further application of VR in science for vocational training or higher education is feasible to engage students or stakeholders from various disciplines.
\end{abstract}

Keywords: Virtual reality, 3Rs principles, Gamification, Simulation, Animal handling, Laboratory safety, Laboratory techniques, Laboratory training, Biomedical science education

\section{Introduction}

The use of animal models is imperative to understand the biology and causes of diseases in biomedical science research. Experimental animal models, such as mice and rats, share many physiological and genetic similarities with a human that are helpful for medical

\footnotetext{
*Correspondence: florencetang@cuhk.edu.hk

${ }^{1}$ Division of Education, School of Biomedical Sciences, Faculty

of Medicine, The Chinese University of Hong Kong, Hong Kong SAR, China

Full list of author information is available at the end of the article
}

science and drug developments. Animal experimentation is conventionally regarded as the golden standard in modern biomedical and pharmaceutical research and has been extensively used since the beginning of the 1980s (Orlans 1993). Hundreds of experiments involved animal models performed every month, however, raising ethical concerns for excessive killing life and leaving animals with untreated pain. Animal rights and welfare advocate that animals are sentient beings in no less than a human with the capacity to experience feelings, and in favour of treating experimental animals with an equal right as a human living in a torture-free and pain-free

c) The Author(s) 2020. This article is licensed under a Creative Commons Attribution 4.0 International License, which permits use, sharing, adaptation, distribution and reproduction in any medium or format, as long as you give appropriate credit to the original author(s) and the source, provide a link to the Creative Commons licence, and indicate if changes were made. The images or other third party material in this article are included in the article's Creative Commons licence, unless indicated otherwise in a credit line to the material. If material is not included in the article's Creative Commons licence and your intended use is not permitted by statutory regulation or exceeds the permitted use, you will need to obtain permission directly from the copyright holder. To view a copy of this licence, visit http://creativeco mmons.org/licenses/by/4.0/. 
environment, promulgate banning animal use in scientific experimentation.

The ethical principles called the 3Rs (namely Replacement, Reduction, and Refinement) are widely adopted to minimise animals suffering in contemporary scientific practice (Goldberg 2010; Whittall 2009). The goal is to improve quality care in the handling of the experimental animals by reducing the numbers of animals used, replacing the use of animals with other in vitro methods and refining training and experiments methods. The guiding principle prohibits excessive use of animals testing for cosmetic purposes, as well as drug testing without anaesthesia or manual skills training (Osborne et al. 2009; Wells 2011). There are a variety of legislative regulations granting the use of experimental animals for scientific purposes with the consideration of 3Rs (Filipecki et al. 2011; Kurosawa 2008).

Continuous training in handling laboratory animals is fundamentally crucial to the responsible use of animals in research. Animal welfare topic is somewhat underdeveloped in the tertiary education curriculum, where primary teaching is majorly delivered in the format of lecture and group discussion (Broom 2005, 2010). With limited hand-on laboratory exposure with laboratory animals, the awareness of the ethical 3Rs principle among students was underperformed. A questionnaire assessed views towards using an animal in medical research among Indian medical students and as little as one-tenth respondents were aware of the presence of ethical guidelines for animal handling and believed that animal research needed stringent regulation (Nerlekar et al. 2018). Some Brazilian students were discomfort in using animals during practical classes and refused to stay in the classroom (Rochelle et al. 2016). These attitudes show the unmet educational effort in addressing ethical reflections through conflicting situations and low moral awareness.

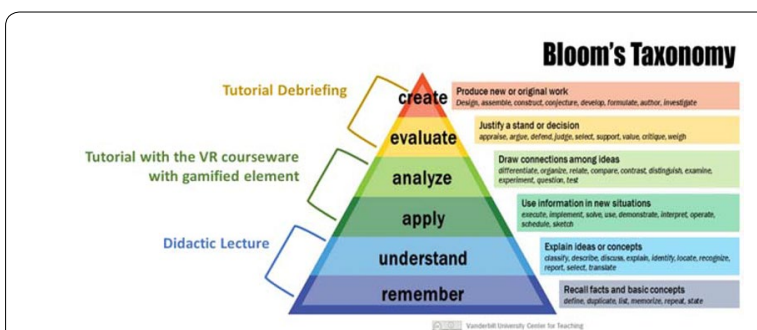

Fig. 1 Alignment gamified VR technology with the 6-stage learning model. (Modified from the Bloom's Taxonomy created by the Vanderbilt University Center for Teaching (Armstrong 2001))

\section{Conceptual theories underlying the project}

Virtual reality (VR) technology is a computer-generated interface, enhancing visual stimulation by immersing the user's perception inside a three-dimensional (3D) environment (Seth et al. 2011). It offers a great alternative approach to support learning by creating telepresence environment and has been widely adopted both in the training and educational purposes. The strategy of using VR as a learning tool was documented more than 40 years, and the expensive cost forbidden its full extent diffusing at the application level (Dalgarno and Hedberg 2001). As VR hardware cost substantially drops and becomes affordable (Earnshaw 2014), it leads to a paradigm shift in adopting simulation at the museums and cultural heritage settings (Economou and Pujol, 2008), work-based professional training, such as surgical training (Tergas et al. 2013), aviation (De Repentigny et al. 2003), police and military (Garcia et al. 2019; Smith and Carter 2010) and dental education (Buchanan 2004). VR has a fundamental value in academia to engage students in learning activities through immersive simulation (Allcoat and von Mühlenen 2018). Studies have shown that the immersive experience engaged students better, gauged attention, spent more time on the learning tasks and acquired better cognitive, psychomotor and affective skills (Bester and Brand 2013; Radianti et al. 2020).

Gamification is an evolving concept that applies digital game format in the academic field of study in the past 2 decades (Seaborn and Fels 2015), and the primary aim is to drive participatory learning by applying new skills through action. Figure 1 describes the cognitive-action learning process in knowledge mastery augmented to the educational philosophy called Bloom's taxonomy (Armstrong 2001). In the learning pyramid, two fundamental elements in acquiring new information knowledge through memorisation and comprehension. A deeper understanding involves triangulation of conceptual information through procedural learning from putting knowledge in action and critical analysis. Then, a continual evaluation and idea development are required to digest the information using personalised interpretation method to maintain knowledge retention. Incorporating gamified element in the face-to-face pedagogy translates learning into practice progressing from each stage through continuous stimulation of perception, application of knowledge, reaction to new information, and reward motivation, and promotion of higher-order thinking (Taylor and Curran 2016). Bloom's taxonomy as a guiding principle is beneficial in the design of learning objective when applying gamification in the traditional passive classroom teaching.

Educators from different disciplines have applied gamification research in education. A team conducted a 
large-scale randomised collected experiment in assessing learning efficacy using a game badge-based scoring system in a population health course (Denny 2013). Students were instructed to complete at least 20 questions in the assignment. Students were randomly allocated into an experimental "badge-on" group, which received notifications for very new badge earned; or control "badge-off" group, which no badge was given. Study findings showed that the badge-based scoring was a pervasive strategy in motivating answers submission and engagement with a consistent quality response. Another study evaluated the gamified courseware in anatomy learning and reported that designing quizzes in a game format encouraged repeated revision attempts, which had a positive motivational influence in the knowledge mastery (Ngan et al. 2017). A review on empirical works in applied gamification showed that majority were grounded on four goals, namely encouraging end-user participation, changing behaviour, promoting fun learning atmosphere and tracking response (Seaborn and Fels 2015). The efficacy of gamification was mostly positive, although the reported mixed results could be explained by varying learning needs in different disciplines.

Animal experimentation is one of the core topics in the biomedical sciences curriculum. In the past, students use real animals to learn the laboratory care and management of animals. When learning about animal welfare and related ethical issues, the theoretical framework is passively taught by conventional didactic methods that proper etiquette in animal handling was not taught effectively. Although the principle of 3 Rs was developed over 50 years, researchers always neglect such principles and overuse animal models in experiments. Very often, university students did not have prior laboratory experience that they barely able to relate themselves as the future scientist or laboratory researchers. Very often, they felt distanced about their responsibility in refraining from overusing animals.

The hybrid uses of VR technology with gamification, together with didactic pedagogy, offer promise in enforcing working knowledge into better task performance, specifically research skills training. The VR environment creates an abundance of interactions in the digital world, and the gamified elements gauge students' learning engagement. Blending VR with the gamification concept could be a modernised pedagogy in training animal experimental skill, promoting animal welfare awareness through a proactive spiral learning setting through engaging students to understand an assigned task, identifying problems and looking for a solution. This paper describes a multi-disciplinary experience in developing and implementing virtual reality (VR) simulation to enhance contextual learning of using animal models in research with digital technology in biomedical science teaching at higher education.

\section{Courseware development and instructional design for animal holding training} The setup of the immersive VR system: HTC VIVE ${ }^{\circledR}$

The development of VR adopts VIVE ${ }^{\circledR}$ released by HTC and Valve Corporation (see Fig. 2). The VIVE ${ }^{\circledR}$ system uses the organic light-emitting diode display providing about 110 degrees field of view, as well as a built-in microphone and front-facing camera for embedding the user's perception in the world of virtual reality. After placing the two-stationary sensors of the VIVE ${ }^{\circledR}$ system at a $4 \times 3 \mathrm{~m}$ in the diagonal unit open space, the headset and handheld controllers, the user with the backpack computer, headset and track controller can immerse, react, interact and sense freely in the virtual world. This technology has been used in other medical applications (Egger et al. 2017; Niehorster et al. 2017). The backpack computer let the user move freely; the headset with two miniatures display makes the user having stereo physical sensation; motion tracker detects the user's position, and the controller trigger leads the user to respond interactively in the virtual environment.

\section{The setup of game engine}

Game engine software is required to support the animation, optimised graphics and real-time physics. There are many game engines software-supported VR development, such as CaveUT (Jacobson et al. 2005), Unity (Wang et al. 2010), CryEngine (Juarez et al. 2010) and Unreal Engine 4 (Ponder et al. 2003). Among all, the latest version of Unreal Engine 4 software selected for better three-dimensional rendering capabilities, secondly, great visual graphics for real-time reflection; and compatible with interaction collision (Mól et al. 2008).

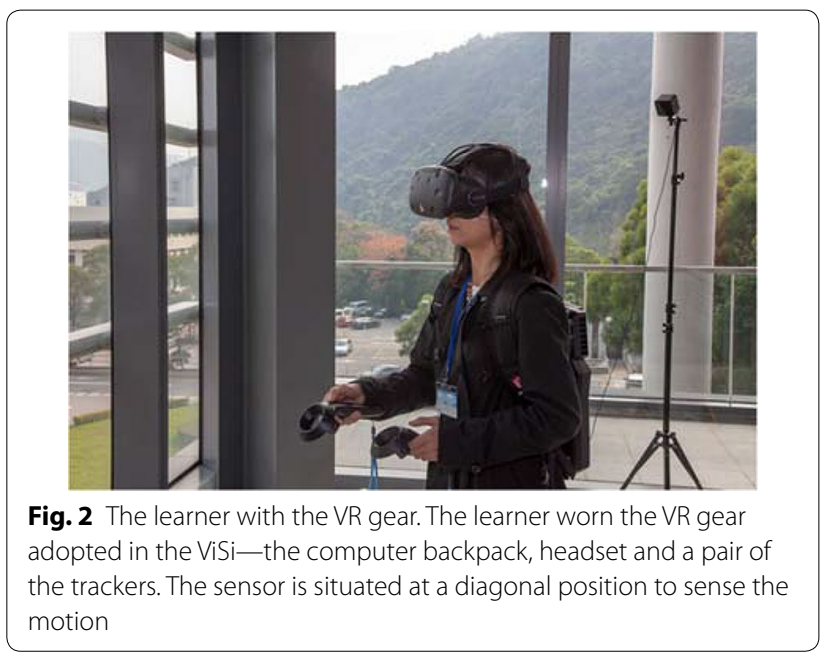




\section{The gamification element for the ViSi}

The courseware called virtual animal holding gamified simulator $(\mathrm{ViSi})$ consists of two learning environments that could also be considered as two game levels. In the first game level, the setting situates on the preparation room, and the learner is instructed to put on essential personal protection equipment (PPE) and transfer the requested animals to the trolley before entering the restricted area. In the next game level, the setting situates at the restricted area called the experimental room for performing animal experiments. If the learner fails to pick up appropriate PPE or put the coke onto the trolley, the learner is forbidden to enter to the handling room for proceeding the experiment.

The ViSi is also a learner-centred game design that the digital output of the interaction response by learner would also be displayed to the monitor using the Miracast technology. In other words, the teacher and classmates simultaneously observe what the learner did so that parallel teaching could be taken place commenting on his/her correct or wrongdoing actions.

\section{Game level I: the preparation room}

The VR experience begins once the learner wears the gear. Before entering the preparation area, a message asks whether the learner has applied for animal experiment licence granted by the Government and the ethical approval by the university's Animal Experimentation Ethics Committee (AEEC). $\mathrm{He} / \mathrm{she}$ is also advised to attend the institutional introductory training of using animal holding facilities and adhere to the institutional and regional regulation guideline related to the animal's experiments. Figure 3 shows a question checklist related to animal experimentations to remind what paperwork a researcher should obtain before conducting animal experiments. Access will be granted to the user when meeting the three requirements: (1) complete training, (2) seek the senior support and (3) apply institutional ethics clearance. After noting all the essential administrative work for the ethics of animal research, the learner will proceed to the next stage.

Next, the learner needs to apply the laboratory safety knowledge and choose appropriate PPE to put on before entering the experimental room. Among the options in the table (Fig. 4a) the learner needs to select the proper PPE on the table, which are disposable cap, disposable outerwear, gloves, mask and foot cover (Fig. 4b). If he/she chooses the incorrect item on the table, such as drink, one is forbidden to enter the subsequent stage as food and beverages are prohibited during the experimental area. Then, the learner is expected to prepare essential experiment equipment and put on the trolley. Correct items include a delivery cage with mice, two empty animal cages, a bottle of Drug A and saline and syringe needles. When a red warning card hangs on the cage, it warns the learner to pay attention to taking care of the sick animal in the care (Fig. 4c). After the learner picked up all correct items (Fig. 4d), the learner would gain access to the next game level.

\section{Game level II: the experimental room}

The learner conducts the virtual hands-on experimental procedures at this stage. He/she learns fundamental knowledge in distinguishing the male and female mouse from the external features and different injection methods. For example, a photograph will be displayed to teach the learner the proper injection position (Fig. 4e). The subsequent instruction pops out and informs the learner to inject drug A or the saline on the mice and transfers the injected mice to the appropriate cages for the experimental/control experiments (Fig. $4 \mathrm{f}-\mathrm{g}$ ). After completing the task, the learner puts the used syringe with a needle to the sharp disposable box for the laboratory safety concern (Fig. 4h). The experimental and control cage should be moved to the holding rack that marked the end of the whole simulation experience.
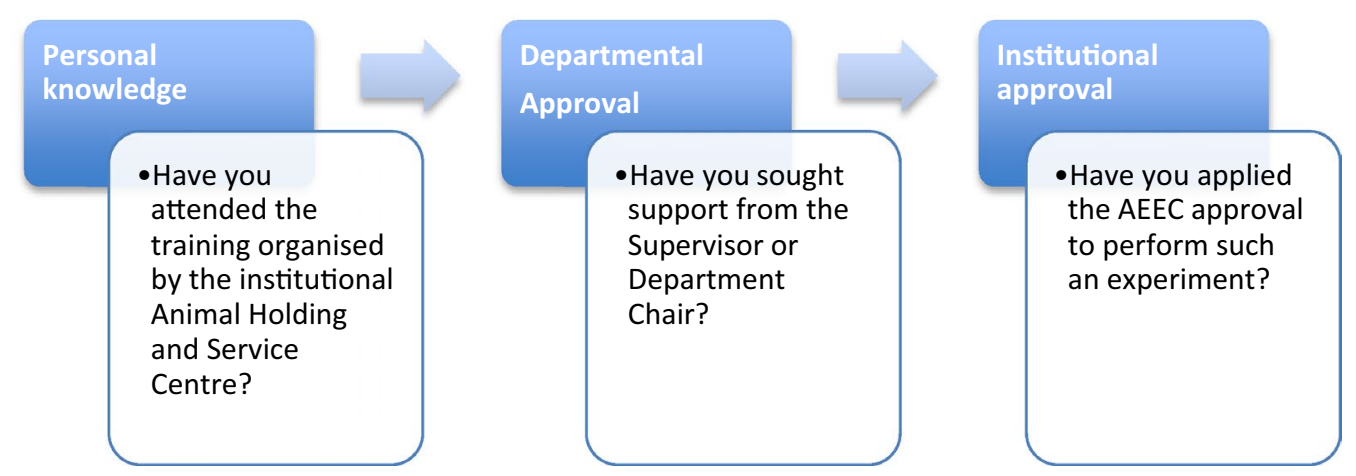

Fig. 3 Question checklist related to animal experimentations 

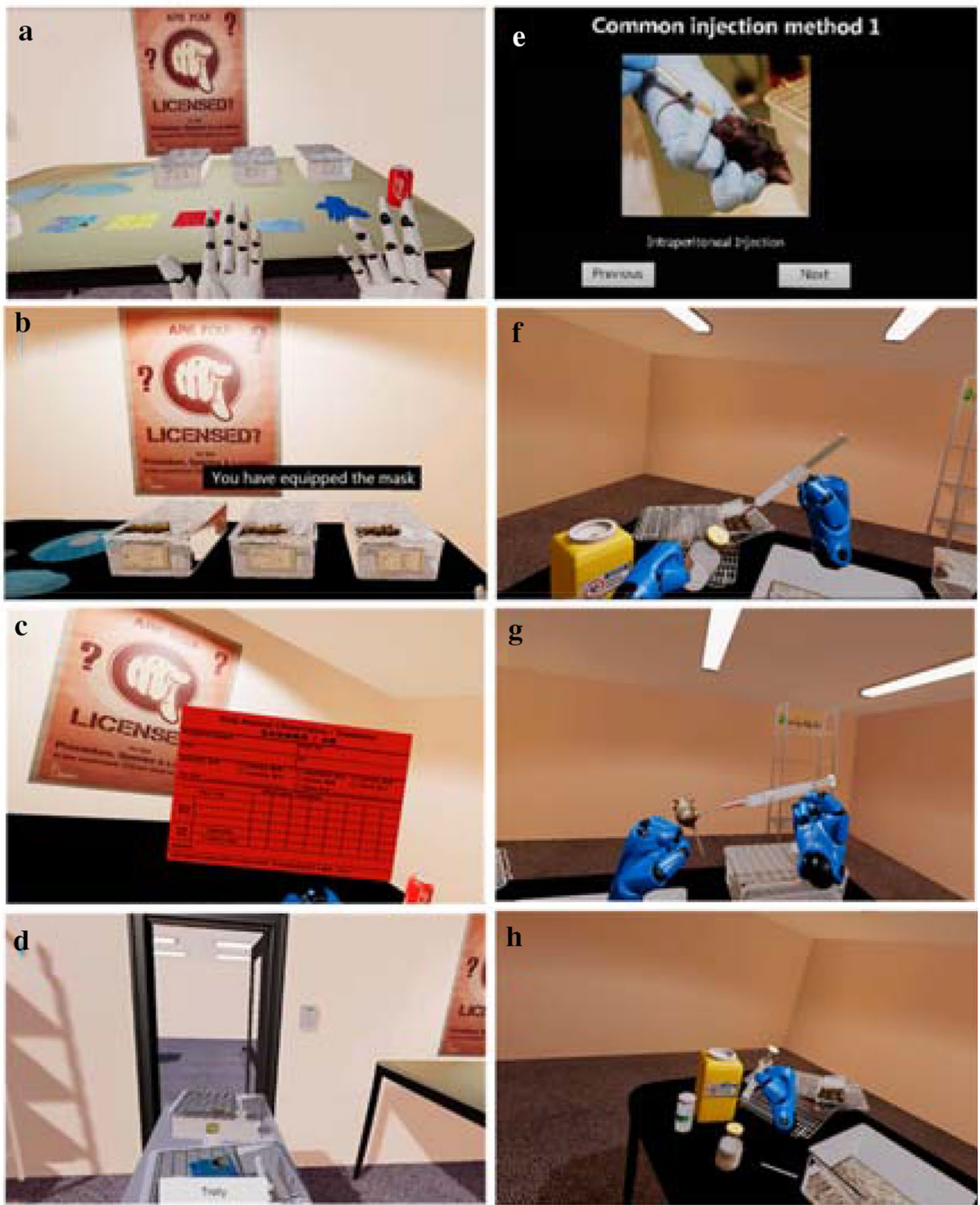

Fig. 4 VR game design. a-d The logistic flow of preparation area: $\mathbf{a}$ the learner chooses the appropriate PPE to wear; $\mathbf{b}$ learner prepares the equipment; $\mathbf{c}$ learner picks up the warning red card; $\mathbf{d}$ the learner moves to the experimental room with the trolley. $\mathbf{e}-\mathbf{h}$ The logistic flow of the experimental room: $\mathbf{e}$ the injection method; $\mathbf{f}$ the learner takes the drug A with a syringe; $\mathbf{g}$ the injection method and $\mathbf{h}$ how the learner to dispose of the used syringe to the yellow disposable sharp bottle

\section{Courseware implementation framework Course and students users}

The courseware was adopted in a session called "The Use and Care of Laboratory Animals" under the course "Techniques in Biomedical Research", teaching arrays of laboratory research methods. The overall teaching objectives of this topic are to equip students with proper laboratory etiquette and practice in handling experimental animals. A total of 28 Year 2 students (the entire cohort) enrolled at biomedical sciences programme were invited to share their learning experience informally during the debriefing. Prior to the course, students did not have prior exposure in laboratory settings that they did not have experience in taking care of laboratory animals. 


\section{Students' experiential learning}

At the lecture, a historical and evolving landscape of how animal models contributed to scientific discovery, biomedicine breakthroughs and drug development was covered. In addition to the research techniques, local and institutional frameworks governing the laboratory animal services at the practical level were included. Figure 1 describes how the gamified VR technology designed is aligned with the cognitive process when attaining new information under the Bloom's taxonomy. At this stage, students received factual knowledge and the crucial role of involving animals in basic science research, where they are situated at stage 1 - remember - and stage $2-$ understand - under the Bloom's taxonomy (see Fig. 1).

Followed by the lecture was the tutorial, where the courseware was adopted, providing students with a simulated setting to the laboratory and engaged research experiments. A student was selected to wear the headset, immersed in an animal house and followed the instruction to perform injections on the mice after putting on the personal protective equipment. This is the time point where students begin interacting with the VR animal handling courseware. Through the virtual experiential, the learner enjoyed the whole experience beginning from applying animal ethics clearance, handling laboratory animals and performing experiments. At this stage, students applied research techniques and concepts learnt from the lecture through the gamified VR simulation. Incorrect behaviour or performance was rectified through the process. During the time, the student interaction was projected on the screen, where the teacher facilitated the discussion with other classmates (See Fig. 5). Students would move up the Bloom's taxonomy pyramid to stage 3 -apply - and stage 4 - analyse.

Followed next was a debriefing session, which enabled immediate reflection when the impression was fresh on the minds. Teachers acted as a facilitator, inviting student-learner and student-observers to share their experience and observation during the simulation based on the role of a researcher. At this stage, students could evaluate and reflect on the excessive use of animals in science, specifically on the research without scientific rigour. The 3Rs principles were reinforced as a sample framework for performing human animal research. Students would adopt higher cognitive learning at stage 5evaluate-and stage 6-create-in Bloom's taxonomy.

\section{Integrating $3 R s$ with the gamified VR in animal handling}

The courseware provides a virtual reality simulation allowing students to receive laboratory exposure in doing experiments that involve animals, where they have never been practised before. Students were able to engage in the skill learning activity and be sensitive to animal

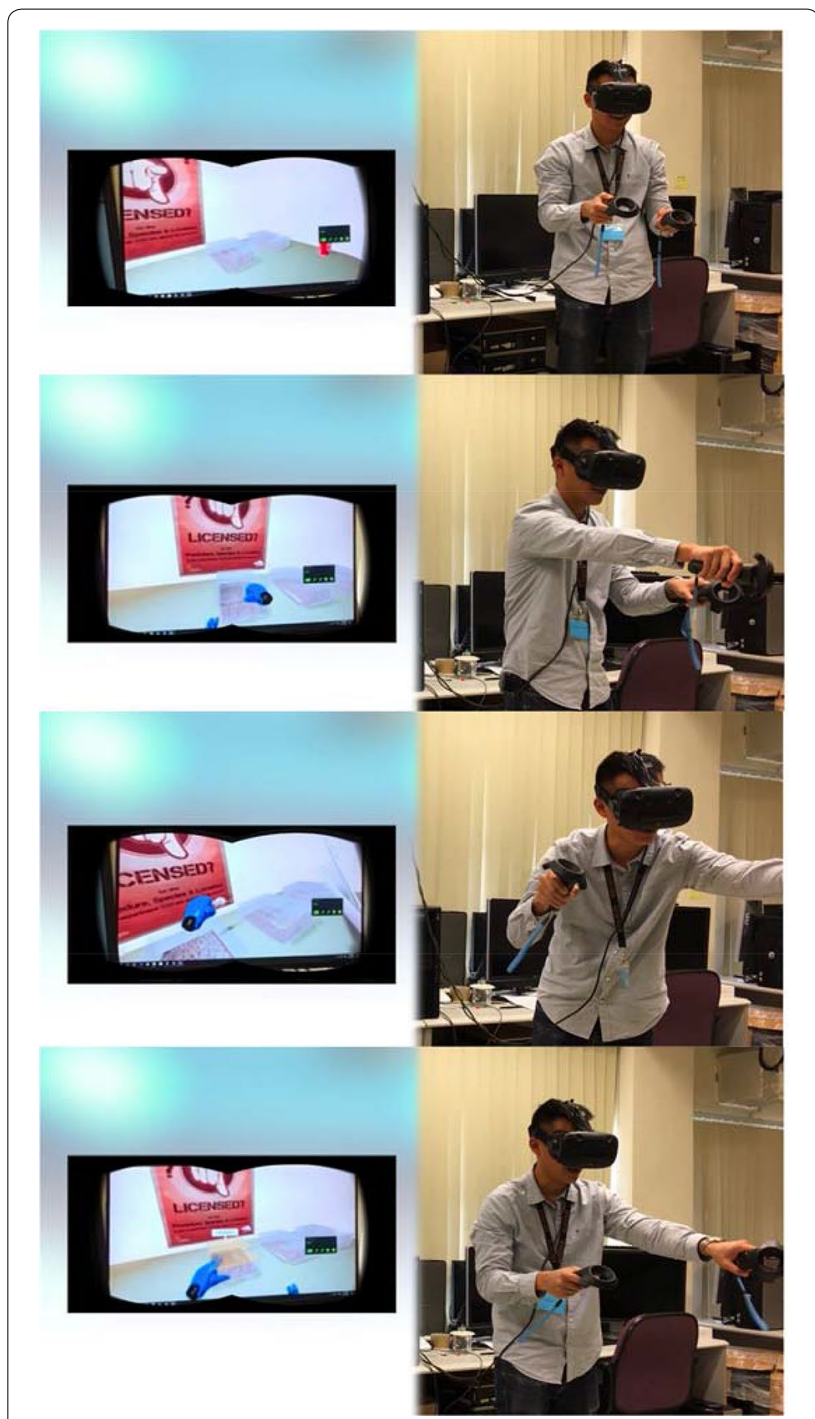

Fig. 5 Student-learner in the VR simulation at the tutorial

welfare. At the debriefing, the following were reinforced, highlighting how gamified VR technology assists the conventional teaching pedagogy and aligns with the 3Rs ethical principles.

\section{Replacement}

ViSi replaces the use of animal models in teaching. The animal handling experiments originally involve an actual injection of saline and Drug A to real mice. With ViSi, the hands-on experiments are replaced by digital games. Students can use ViSi to experience the feeling of animal experiments. In this way, technology helps reduce the number of mice manipulated, and thus minimising animals' pain, suffer, fear and stress, no matter for research use or teaching use, 
hence alleviate ethical concerns in animal welfare. During the debriefing, students were asked to reflect rationally on the imperative role that experimental animal in advance of science and possible ways to strike a balance between two issues.

\section{Reduction}

The content reflects how important 3Rs principles are, particularly in reduction. The VR simulation facilitates the learning of animal handling techniques and avoids the use of mice merely for non-scientific purposes, such as teaching. Every time when scientists utilise animals in research, good practice should be upheld so that no animal will be harmed or wasted. Having a corrupted practice or incidents such as injecting the wrong solution does not merely abandon an animal model but also sacrifice a valuable life. With this courseware, students may receive a simulated practice to gain the value of experience in learning technical skills and be cautious about the implication of using animals.

\section{Refinement}

Intraperitoneal injection in the gamification plays a vital role in alleviating unnecessary animal torture. Through this simulation, teaching can highlight the precautions in handling experimental animals, such as to inject the needle cautiously and place the mouse into an appropriate cage that contains comfortable beddings. These procedures ensure animals are treated humanely with benevolence and compassion. During the briefing, teachers can elaborate on procedural details with a touch on personal experience, and students engage in peer communication discussing potential problem issues in science that involve with or without experimental research. The courseware provides a room of imagination in reflection the role of animal model in science, which ViSi demonstrates a good alternative in refining teaching quality.

\section{Reflection from experiential learning Institutional experience: revolutionising conventional classroom teaching}

Effective teaching in animal handling skills is resourceintensive, and junior students might have never received an opportunity to expose in the laboratory with experimental animals. Often, using real animals are discouraged in the teaching as animal uses can only be approved with a robust scientific aim by the Animal Experimentation Ethics Committee. Teaching purposes, such as drug injection training and observation of clinical signs or behaviours, are not permitted to exacerbate harms on animals. In other words, students might not be able to conceptualise theory through hands-on learning activities on problem-solving tasks. As few as it gets, the conventional teaching method relies on didactic lecture method, watching a video in the classroom. The one-way communication in passive learning largely limits the delivery of knowledge, where students passively learn the underlying theory or technique (Pelley 2014). Without an early exposure of hands-on experience to assimilate information and make meaning of the tasks, students cannot rehearse leaning material or overcome fear response in handling or restraining animals (such as mice). Applying VR in the animal handling courseware is potentially beneficial in addressing the learning needs and gap in the higher education setting. From the student users' perspective, fostering experiential learning is a primary advantage. Other reported benefits include immersive laboratory experience and peer learning through gamification.

\section{Student voices: implications from the in-class experience}

Our in-class experience was that students engaged in experiential learning when the game elements incorporated problem-solving tasks. An advantage of gamified VR simulation is to allow students exposed in enhanced fun searching atmosphere, increased learning concentration and retention time for memorisation, as well as prolonged sensory constellations over the hands-on work (Goswami 2008). In specific to our context, students felt beneficial in learning by translating book concept knowledge to the simulated setting, which is not delivered through traditional classroom teaching medium by PowerPoint presentation and textbooks (Yahaya and Ahmad 2017). A small number of students, however, did not grasp the core idea after the simulation. A debriefing session performed after the tutorial effectively helped clarify in the value exploration of in favour or against the use of animals is honestly represented. Overall, the complementary role of the gamified VR technology along with the didactic pedagogy received positive feedback. Students also shared that the VR courseware allowed them to relate themselves as a researcher in handling animal at the laboratory. It particularly helped them familiarise the indispensable role of experimental animals in animals and integrating the $3 \mathrm{R}$ principles in the research design.

Some students encountered difficulties in concentrating and adjusting in the VR simulation. This could be potentially explained by the cybersickness, where they lost spatial awareness of the room and felt vision fatigue due to the motion sickness inside the headset while playing for an extended period. For example, students felt dizzy as their quick movement did not reflect in simultaneously in the virtual world. A possible solution is to decrease the simulation period within a reasonable time frame to prevent the uncomfortable disorientation (Reason and Brand 1975). Our experience in setting the game 
within $10 \mathrm{~min}$ to complete the game is reasonable and drive good response. Current VR hardware remains limited that restricted movement within a confirmed space in this study. The technical limitations should be short term and could be resolved when VR hardware advances addressing the delay reflection between actual motion and virtual detection (Earnshaw 2014). The second wave of immersive VR will boost the high impact on students' curiosities and excitements once the maturation of the support of hardware and software launched to the commercial market in the future.

\section{Study limitations}

This paper describes the courseware targeting the training gap of animal ethics in higher education. The ViSi represents an excellent example of how gamified VR technology enhances the learners' multi-cognition in learning. More importantly, it provides a novel strategic pedagogy for other broad-based techniques in research activities in biotechnology, improves the quality of teaching and encourages active learning and intellectual exchange between teachers and students. The focal point of this paper is to describe the conceptual framework underpinning the courseware development and report institutional experience in incorporating the gamified VR technology in biomedical science education. We did not conduct a systematic evaluation assessing students' feedback using a structured empirical method, where the reported students' experience was collected through the debriefing session, a rather informal setting. The preliminary positive feedback was, nonetheless, valuable and useful informing learning the implications of science technology in the teaching arm. Further studies in assessing the parallel arm of the art in empathy and emotion towards the ethics of using animals for experimental purposes shall be convened.

\section{Conclusion and further implications}

The setup of innovative gamified VR simulation is in line with the explorative information technologies. The simulation is situated at the animal holding core facility, teaching laboratory skills on the usage of animals by in compliance with 3Rs principles. Our experience in incorporating digital technology in education allows students to learn by doing through simulation. Students shared that they were satisfied with teaching quality with additional sensory reception and felt seamlessly integrated into the virtual. From that perspective, using gamified VR simulation enhances blended pedagogic strategies in the curriculum development at departmental, faculty and university level (Lim et al. 2019).

\section{Acknowledgements}

We thank student helpers assisted in piloting the courseware and Korea National University of Education in supporting the publication charges.

\section{Authors' contributions}

MKT conceptualised and supervised the project. MFL, HKS and CTC contributed to the technical development of the courseware. MKT and OMYN made a substantial contribution to the manuscript. All authors read and approved the final manuscript.

\section{Funding}

This project is supported by the Micro-module Courseware Development Grant, the Chinese University of Hong Kong. The funder has no role in courseware development and manuscript writing.

Availability of data and material

Not applicable.

\section{Competing interest}

The authors declare that they have no competing interests.

\section{Author details}

${ }^{1}$ Division of Education, School of Biomedical Sciences, Faculty of Medicine, The Chinese University of Hong Kong, Hong Kong SAR, China. ${ }^{2}$ Information Technology Services Centre, The Chinese University of Hong Kong, Hong Kong SAR, China. ${ }^{3}$ Department of Computer Science and Engineering, Faculty of Engineering, The Chinese University of Hong Kong, Hong Kong SAR, China. ${ }^{4}$ CUHK Centre for Bioethics, Faculty of Medicine, The Chinese University of Hong Kong, Hong Kong SAR, China.

Received: 28 December 2019 Accepted: 26 October 2020 Published online: 25 November 2020

\section{References}

Allcoat, D., \& von Mühlenen, A. (2018). Learning in virtual reality: Effects on performance, emotion and engagement. Research in Learning Technology. https://doi.org/10.25304/RLT.V26.2140.

Armstrong, P. (2001). Bloom's taxonomy. Center for Teaching, Vanderbilt University. Retrieved on October 14, 2020 from, https://cft.vanderbilt edu/guides-sub-pages/blooms-taxonomy/.

Bester, G., \& Brand, L. (2013). The effect of technology on learner attention and achievement in the classroom. South African Journal of Education 33(2), 1-15.

Broom, D. M. (2005). Animal welfare education: Development and prospects. Journal of Veterinary Medical Education, 32(4), 438-441. https:// doi.org/10.3138/jvme.32.4.438

Broom, D. M. (2010). Animal welfare: An aspect of care, sustainability, and food quality required by the public. Journal of Veterinary Medical Education, 37(1), 83-88. https://doi.org/10.3138/jvme.37.1.83.

Buchanan, J. A. (2004). Experience with virtual reality-based technology in teaching restorative dental procedures. Journal of Dental Education, 68(12), 1258-1265. https://doi.org/10.1002/j.0022-0337.2004.68.12. tb03875.x.

Dalgarno, B., \& Hedberg, J. (2001). 3D learning environments in tertiary education. Paper presented at the Australian Society for Computers in Learning in Tertiary Education: Meeting at the crossroads. Melbourne: Biomedical Multimedia Unit, The University of Melbourne, pp. 33-36. Retrieved on September 10, 2020 from, https://researchoutput.csu.edu. au/en/publications/3d-learning-environments-in-tertiary-education.

De Repentigny, L., Pearson, G., \& Wilks, B. (2003). Using simulation as an effective runway incursion prevention strategy. Paper presented at the AIAA modeling and simulation technologies conference and exhibit. Retrieved on September 14, 2020 from, https://doi. org/10.2514/6.2003-5599.

Denny, P. (2013). The effect of virtual achievements on student engagement. Paper presented at the Proceedings of the SIGCHI conference on human factors in computing systems, Paris, France. Retrieved on October 14, 2020 from, https://doi.org/10.1145/2470654.2470763.

Earnshaw, R. A. (2014). Virtual reality systems. London: Academic Press. Economou, M.\& \& Pujol, L. (2008). Educational tool or expensive toy? Evaluating VR evaluation and its relevance for virtual heritage. In Y. E. Kalay, T. Kvan, \& J. Affleck (Eds.), New heritage: New media and cultural heritage (pp. 242-260). London: Routledge. 
Egger, J., Gall, M., Wallner, J., Boechat, P., Hann, A., Li, X., et al. (2017). HTC Vive MeVisLab integration via OpenVR for medical applications. PLOS ONE, 12(3), e0173972.

Filipecki, A. T. P., Machado, C. J. S., Valle, S., \& Teixeira, Md O. (2011). The Brazilian Legal Framework on the scientific use of animals. Institute for Laboratory Animal Research Journal, 52(1), E8-E15. https://doi. org/10.1093/ilar.52.1.E8.

Garcia, E. T., Ware, S. G., \& Baker, L. J. (2019). Measuring presence and performance in a virtual reality police use of force training simulation prototype. Paper presented at the 32nd international Flairs Flordia artificial intelligence research society conference.

Goldberg, A. M. (2010). The principles of humane experimental technique: Is it relevant today? Alternatives to animal experimentation, 27(2), 149-151. https://doi.org/10.14573/altex.2010.2.149.

Goswami, U. (2008). Principles of learning, implications for teaching: A cognitive neuroscience perspective. Journal of Philosophy of Education, 42(3-4), 381-399. https://doi.org/10.1111/j.1467-9752.2008.00639.x.

Jacobson, J., Le Renard, M., Lugrin, J. L., \& Cavazza, M. (2005). The CaveUT system: Immersive entertainment based on a game engine. Paper presented at the proceedings of the $2005 \mathrm{ACM}$ SIGCHI international conference on advances in computer entertainment technology. Retrieved on March 15, 2020 from, https://doi.org/10.1145/1178477.1178503.

Juarez, A., Schonenberg, W., \& Bartneck, C. (2010). Implementing a low-cost CAVE system using the CryEngine2. Entertainment Computing, 1(3-4), 157-164. https://doi.org/10.1016/j.entcom.2010.10.001.

Kurosawa, T. M. (2008). Japanese regulation of laboratory animal care with 3Rs. Japanese regulation of laboratory animal care with 3 Rs. In Alternatives to animal testing and experimentation, proceeding of the 6 th world congress on alternatives \& animal use in the life sciences, pp. 317-321.

Lim, C. P., Wang, T., \& Graham, C. (2019). Driving, sustaining and scaling up blended learning practices in higher education institutions: A proposed framework. Innovation and Education, 1(1), 1-12. https://doi. org/10.1186/s42862-019-0002-0.

Mól, A. C. A., Jorge, C. A. F., \& Couto, P. M. (2008). Using a game engine for VR simulations in evacuation planning. IEEE Computer Graphics and Applications, 28(3), 6-12.

Nerlekar, S., Karia, S., Harshe, D., Warkari, R., \& Desousa, A. (2018). Attitude and knowledge of undergraduate medical students towards the use of animals in medical research: An exploratory study. Journal of Clinical \& Diagnostic Research. https://doi.org/10.7860/jcdr/2018/32260.11768.

Ngan, O. M. Y., Tang, T. L. H., Chan, A. K. Y., Chen, D. M., \& Tang, F. M. K. (2017). Blended learning in anatomy teaching for non-medical students: An innovative approach to the health professions education. Health Professions Education, 4(2), 149-158. https://doi.org/10.1016/j. hpe.2017.11.001.

Niehorster, D. C., Li, L., \& Lappe, M. (2017). The accuracy and precision of position and orientation tracking in the HTC vive virtual reality system for scientific research. i-Perception, 8(3), 1-23. https://doi. org/10.1177/2041669517708205.

Orlans, F. B. (1993). In the name of science: Issues in responsible animal experimentation. Oxford: Oxford University Press.

Osborne, N. J., Payne, D., \& Newman, M. L. (2009). Journal editorial policies, animal welfare, and the 3Rs. American Journal of Bioethics, 9(12), 55-59. https://doi.org/10.1080/15265160903318343.

Pelley, J. (2014). Making active learning effective. Medical Science Educator, 24(1), 13-18. https://doi.org/10.1007/s40670-014-0087-1.
Ponder, M., Papagiannakis, G., Molet, T., Magnenat-Thalmann, N., \& Thalmann, D. (2003). VHD ++ development framework: Towards extendible, component based VR/AR simulation engine featuring advanced virtual character technologies. Paper presented at the Computer Graphics International. Retrieved on March 15, 2020 from, https://doi. org/10.1109/CGI.2003.1214453.

Radianti, J., Majchrzak, T. A., Fromm, J., \& Wohlgenannt, I. (2020). A systematic review of immersive virtual reality applications for higher education: Design elements, lessons learned, and research agenda. Computers \& Education. https://doi.org/10.1016/j.compedu.2019.103778.

Reason, J. T., \& Brand, J. J. (1975). Motion sickness. London: Academic press.

Rochelle, A. B. F., Pasian, S. R., Silva, R. H. A., \& Rocha, M. J. A. (2016). Perceptions of undergraduate students on the use of animals in practical classes. Advances in Physiology Education, 40(3), 422-424. https://doi. org/10.1152/advan.00019.2016.

Seaborn, K., \& Fels, D. I. (2015). Gamification in theory and action: A survey. International Journal of Human-Computer Studies, 74, 14-31. https://doi. org/10.1016/j.ijhcs.2014.09.006

Seth, A., Vance, J. M., \& Oliver, J. H. (2011). Virtual reality for assembly methods prototyping: A review. Virtual Reality, 15(1), 5-20. https://doi. org/10.1007/s10055-009-0153-y.

Smith, S. P., \& Carter, T. (2010). A virtual environment to test police and public awareness of anti-social behaviour indicators. International Journal of Police Science \& Management. https://doi.org/10.1350/ ijps.2010.12.4.196.

Taylor, J., \& Curran, K. (2016). Using leap motion and gamification to facilitate and encourage rehabilitation for hand injuries: leap motion for rehabilitation. In Handbook of research on holistic perspectives in gamifcation for clinical practice (pp. 183-192). Pennsylvania: IGI Global.

Tergas, A. I., Sheth, S. B., Green, I. C., Giuntoli, R. L., Winder, A. D., \& Fader, A. N. (2013). A pilot study of surgical training using a virtual robotic surgery simulator. Journal of the Society of Laparoendoscopic Surgeons, 17(2), 219-226. https://doi.org/10.4293/108680813X13654754535872.

Wang, S., Mao, Z., Zeng, C., Gong, H., Li, S., \& Chen, B. (2010). A new method of virtual reality based on Unity3D. Paper presented at the 18th international conference on geoinformatics. Retrieved on March 15, 2020 from, https://doi.org/10.1109/geoinformatics.2010.5567608.

Wells, D. J. (2011). Animal welfare and the 3Rs in European biomedical research. Annals of the New York Academy of Sciences, 1245(1), 14-16. https://doi.org/10.1111/j.1749-6632.2011.06335.x.

Whittall, H. (2009). Information on the 3 Rs in animal research publications is crucial. American Journal of Bioethics, 9(12), 60-61. https://doi. org/10.1080/15265160903323095.

Yahaya, W. A. J. W., \& Ahmad, A. (2017). Virtual reality courseware towards achievement of transfer learning among students with different spatial ability. Journal of Telecommunication, Electronic and Computer Engineering, 9(2-11), 51-54.

\section{Publisher's Note}

Springer Nature remains neutral with regard to jurisdictional claims in published maps and institutional affiliations.

Ready to submit your research? Choose BMC and benefit from:

- fast, convenient online submission

- thorough peer review by experienced researchers in your field

- rapid publication on acceptance

- support for research data, including large and complex data types

- gold Open Access which fosters wider collaboration and increased citations

- maximum visibility for your research: over $100 \mathrm{M}$ website views per year

At BMC, research is always in progress.

Learn more biomedcentral.com/submissions 